\title{
Identification and Angular Distribution of Residual Radionuclides Detected on the Wall of BATAN's Cyclotron Cave
}

\author{
I. Kambali ${ }^{\star}, H$. Suryanto and Parwanto \\ Center for Radioisotopes and Radiopharmaceutical Technology, National Nuclear Energy Agency \\ Puspiptek Area, Serpong, Tangerang Selatan 15314, Indonesia
}

\section{ARTICLE INFO}

\section{Article history:}

Received 27 March 2015

Received in revised form 30 September 2015 Accepted 15 December 2015

\section{Keywords:}

Cyclotron

Radionuclides

Gamma ray

Cross-sections

Radioactivity

Angular distribution

\begin{abstract}
A B S T R A C T
Detection and measurement of radiation sources around BATAN's cyclotron facilities in Serpong are required as an early step to avoid radiation impacts on the radiation employees who work with the cyclotron. In this paper, radiation emitted from the wall of the CS-30 cyclotron cave are detected and measured using an $\mathrm{NaI}(\mathrm{Tl})$ detector coupled with a pocket multichannel analyzer (MCA) at a counting time of 30 minutes for each sampling point on the wall. The sampling points were in the directions of within $\pm 150^{\circ}$ with respect to the incoming proton beams, and the measurements were conducted at heights between $1.2 \mathrm{~m}$ and $1.8 \mathrm{~m}$ off the floor for every sampling point. The experimental results indicate that Co-60 and Cs-134 detected on the cyclotron cave wall are major radionuclides that contribute to the emitted gamma radiation. The distribution of the gamma ray intensities given off by Co-60 and Cs-134 depend on the angle and position of the sampling points. In general the highest gamma ray rates can be found in the area around $0^{\circ}$ relative to the incoming proton beams. In addition, no other radioactive sources are significantly detected on the wall. The maximum exposure measured on the wall surface was much less than the permissible occupational exposure for radiation workers and general public.
\end{abstract}

(C) 2016 Atom Indonesia. All rights reserved

\section{INTRODUCTION}

The Indonesian National Nuclear Energy Agency (BATAN) has been operating a typical CS30 cyclotron which is based in the Center for Radioisotope and Radiopharmaceutical Technology (PTRR) since 1989. BATAN's CS-30 cyclotron is a circular accelerator that accelerates energetic protons to up to $26.5 \mathrm{MeV}$. The proton beam is then employed in producing medical radionuclides such as $\mathrm{Cu}-64$ and F-18 [1,2] as well as in other research related to materials analysis such as thin layer activation analysis (TLA) and ultrathin layer activation (UTLA) techniques [3,4].

The most common nuclear reactions occurring when protons (in the energy range of between $5 \mathrm{MeV}$ and $30 \mathrm{MeV}$ ) are bombarded into

\footnotetext{
* Corresponding author.

E-mail address: imamkey@batan.go.id

DOI: http://dx.doi.org/10.17146/aij.2016.471
}

target materials are $\mathrm{X}(\mathrm{p}, \mathrm{n}) \mathrm{Y}$ and $\mathrm{X}(\mathrm{p}, 2 \mathrm{n}) \mathrm{Y}$, which can be inferred from the fact that neutrons, particularly fast neutrons, are overwhelmingly generated during the irradiation processes, in addition to particular radionuclides. Neutrons produced from the nuclear reactions are then transmitted into and/or scattered off the target materials. As the composite particles travel through the wall in the cyclotron vault, depending on the particles' energy, secondary radioactive elements may be produced along the uncharged particles' paths. The transport of neutrons in matters can be theoretically calculated using the MCNPX codes [5] whereas the protons' trajectories and range in matters can be simulated using the SRIM codes [6].

Using the MCNPX codes, Martínez-Serrano and co-worker have recently predicted several neutron-induced radionuclides produced on the wall of the cyclotron facility at University of Málaga in Spain [7]. They found that the results of their 
calculations for the depth distributions of the common neutron-induced radionuclides such as Eu152, Eu-154, Co-60, Cs-134, Sc-46, Mn-54, and Zn65 were identical with measurement results for those identified radionuclides, in which their radioactivity concentrations decreased quite steeply with the depth of the wall. For a typical F-18 production, they showed theoretically that the spectrum of neutrons peaked at low energy regimes while the maximum neutron energy was nearly $16 \mathrm{MeV}$.

Radiation detection and measurement of walls surrounding cyclotron machines have been carried out elsewhere, especially in cyclotron facilities overseas. However, most experimental research has been on the depth distribution of the suspected radionuclides [8-10]. While Trnkova et al [8] only identified Bi-204 in the wall of their cyclotron vault apart from a few naturally occurring radionuclides, Yamaguchi and co-workers [9] detected more neutron-induced radionuclides in their wall of interest such as Sc-46, Co-60, Zn-65, Cs-134, Eu-152, Na-22, Mn-54, and possibly Eu154. Nevertheless, only two pronounced radionuclides, Co-60 and Eu-152, were detected by Fujibuchi et al [10].

This research was conducted due to concerns over radiation protection and safety of BATAN's cyclotron workers around the cyclotron area. To the best of the authors' knowledge, proper measurements and identification of the neutroninduced radionuclides on the wall of BATAN's cyclotron cave have not been carried out since the cyclotron was installed in 1989, even though the cyclotron was frequently employed to produce short-lived medical radionuclides such as F-18, Cu64, and Tl-201, as well as to analyze the degradation rate of industrial components, particularly between 1990 and 2005. It is believed that during the irradiation processes, scattered neutrons resulting from the research activities could have activated the chemical elements in the wall; thus, proper detection, measurements, and studies of the radionuclide distribution should be carried out. This paper discusses the neutron-induced radionuclides detected and measured on the wall surface of BATAN's cyclotron vault/cave. The dependence of the radionuclide intensities on the angle of the neutron scattering is also highlighted along with their experimentally measured activities. In addition, a wide range of angular dependence of neutron scattering cross-sections due to thermal and fast neutrons are also simulated using TALYS codes in order to explain the origin of the gamma rays detected on the wall as well as their angular distribution.

\section{EXPERIMENTAL METHODS}

\section{Prediction of possible neutron-induced radionuclides}

Possible radionuclides produced by neutron irradiation can be predicted based on theoretical calculations of nuclear cross-sections. The excitation functions can be derived from the simulation using the TALYS software package that has been widely used and described elsewhere [11, 12]. In this work, the TALYS package was used for simulations for $(p, n),(p, 2 n)$, and $(p, 3 n)$ nuclear reaction modes to investigate the excitation functions of proton-bombarded $\mathrm{Cu}, \mathrm{Fe}, \mathrm{Al}, \mathrm{O}, \mathrm{Tl}$, and some other target materials that may contribute to neutron generation in the cyclotron's vicinity. The protons were assumed to have energies ranging from $1 \mathrm{MeV}$ to $50 \mathrm{MeV}$. This assumption is based on the possible proton energies involved in any nuclear reactions (always above $1 \mathrm{MeV}$ ) and the maximum proton energy produced by BATAN's cyclotron (26.5 MeV), with proton energy range between $26.5 \mathrm{MeV}$ and $50 \mathrm{MeV}$ added for further studies. Meanwhile, various neutron-induced nuclear reactions such as $(n, \gamma),(n, n),(n, p)$, and $(n, 2 n)$ modes were also studied using the TALYS codes, particularly to calculate the nuclear cross-sections of neutron-irradiated elements contained in the wall of BATAN's cyclotron cave. The energies of neutrons included in the simulations were in the thermal and fast regions (between 0 $\mathrm{MeV}$ and $100 \mathrm{MeV}$ ), though most neutrons would probably hit the wall at a maximum energy of almost $16 \mathrm{MeV}$ [7]. In addition, neutron scattering cross-sections were also calculated for several targets, including $\mathrm{Fe}, \mathrm{Ni}, \mathrm{Cr}, \mathrm{Tl}, \mathrm{Cu}$, and Al targets.

\section{Cyclotron cave wall, layout and measurement points}

BATAN's cyclotron is housed in a concrete wall almost $1.9 \mathrm{~m}$ thick, with an area of $6 \mathrm{~m} \times 12 \mathrm{~m}$ and a height of $5 \mathrm{~m}$. The concrete wall is routinely called silica concrete since silicone dioxide $\left(\mathrm{SiO}_{2}\right)$ plays as a major contributor in the concrete mixtures. The complete chemical/atomic composition of the concrete wall is given is Table 1, which indicates that the majority of the concrete wall is composed of atoms commonly used in the design of radiation shielding, such as $\mathrm{O}, \mathrm{Ca}, \mathrm{Mg}, \mathrm{C}$, and $\mathrm{Si}$, though several trace elements are also present in the solid mixtures. 
Table 1. Chemical composition of the BATAN cyclotron's concrete wall [13]

\begin{tabular}{cc}
\hline Chemical Elements & Mass fraction $(\%)$ \\
\hline $\mathrm{O}$ & 35.92 \\
$\mathrm{Ca}$ & 28.02 \\
$\mathrm{Mg}$ & 14.80 \\
$\mathrm{C}$ & 13.55 \\
$\mathrm{Si}$ & 5.25 \\
$\mathrm{Al}$ & 0.88 \\
$\mathrm{Fe}$ & 0.62 \\
$\mathrm{H}$ & 0.48 \\
$\mathrm{~K}$ & 0.22 \\
$\mathrm{Na}$ & 0.14 \\
$\mathrm{Mn}$ & 0.09 \\
$\mathrm{Zn}$ & 0.02 \\
$\mathrm{Co}$ & $1.0 \times 10^{-3}$ \\
$\mathrm{Sc}$ & $2.9 \times 10^{-4}$ \\
$\mathrm{Cs}$ & $1.2 \times 10^{-6}$ \\
$\mathrm{Eu}$ & $5.2 \times 10^{-8}$ \\
\hline
\end{tabular}

Since the cyclotron is not self-shielded, neutrons generated from the proton-irradiated targets are expected to scatter off the entire vault. In this experiment, the neutron-induced radionuclides are detected at various points on the wall's surface at various angles ranging from $-150^{\circ}$ to $150^{\circ}$, in $15^{\circ}$ increments, with respect to the incoming proton beams (Fig. 1).
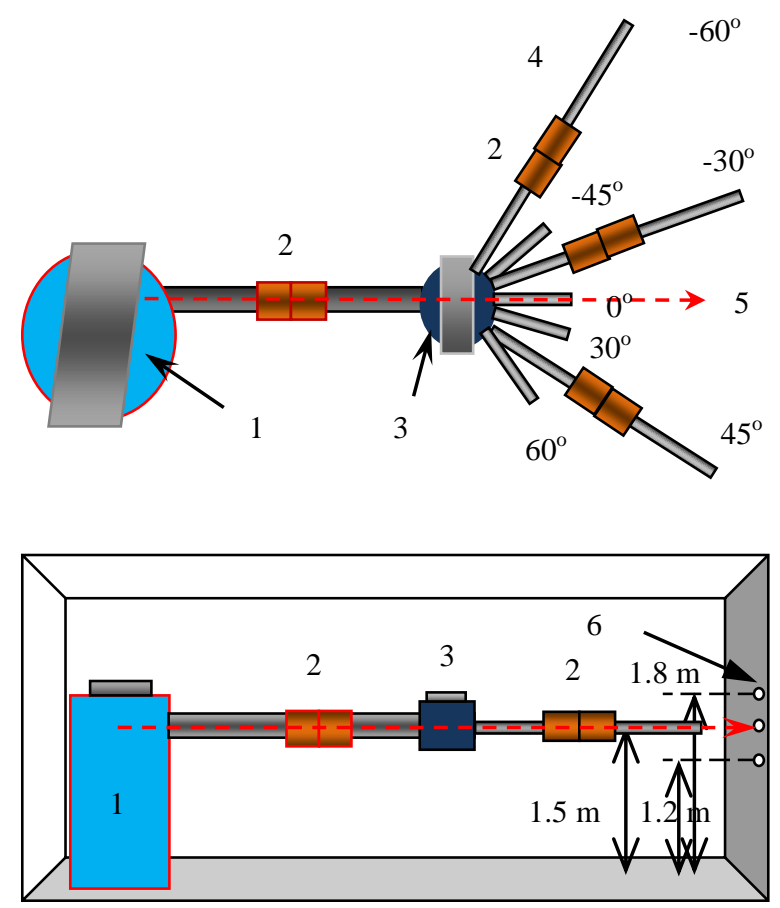

Fig. 1. Cyclotron layout (top) and measurement points (bottom). In the figure, (1) is cyclotron chamber/tank, (2) quadrupole magnet, (3) switching magnet, (4) beam lines, (5) proton beam, (6) measurement points.

Note that all angles in the clockwise direction are called positive angles such as $0^{\circ}, 30^{\circ}$, and $60^{\circ}$, whereas the angles in the opposite direction (counterclockwise) are called negative angles such as $-30^{\circ},-45^{\circ},-60^{\circ}$ and so on. For every angle, the measurement was done at three different heights, i.e., $1.2 \mathrm{~m}, 1.5 \mathrm{~m}$, and $1.8 \mathrm{~m}$ relative to the floor of the cyclotron cave. Note that during radionuclide production using energetic proton beams, most targets were confined in or attached to a holder that was placed at $0^{\circ}$ at a height of $1.5 \mathrm{~m}$ off the floor. The whole measurements were conducted in January 2015. No significant counting corrections were required since radionuclides predicted to be present on the wall were long-lived radionuclides. In addition, calculated results indicated that the radioactive decay processes did not significantly contribute to the counting corrections; thus, this typical assumption was correct.

\section{Detection and measurement system}

The detection and measurements of the radioactivity were carried out using a portable gamma spectroscopy system consisting of a $\mathrm{NaI}(\mathrm{Tl})$ that was connected to a multichannel analyzer (MCA) covering the energy range of between 0 and $2 \mathrm{MeV}$ with an energy resolution of nearly $70 \mathrm{keV}$ around the peak of a Cs-137 source $(E \gamma=0.662$ $\mathrm{MeV})$. The spectroscopy system was calibrated using three gamma peaks from Co-60 $(\mathrm{E} \gamma=1.17$ $\mathrm{MeV}$ and $1.33 \mathrm{MeV})$ and Cs-137 $(\mathrm{E} \gamma=0.662 \mathrm{MeV})$ radioactive sources. The gamma energy spectrum of Co-60 and Cs-137 and the MCA calibration curve are shown in Fig. 2. The linearity of the relationship between channel number and gamma ray energy for the Amptek MCA is, generally speaking, very good as can be seen from its $\mathrm{R}^{2}$ value which equals 0.9952 ; its corresponding linear equation is $y=0.001758 x-0.03412$, where $x=$ channel number on the MCA and $y=$ gamma ray energy $(\mathrm{MeV})$.

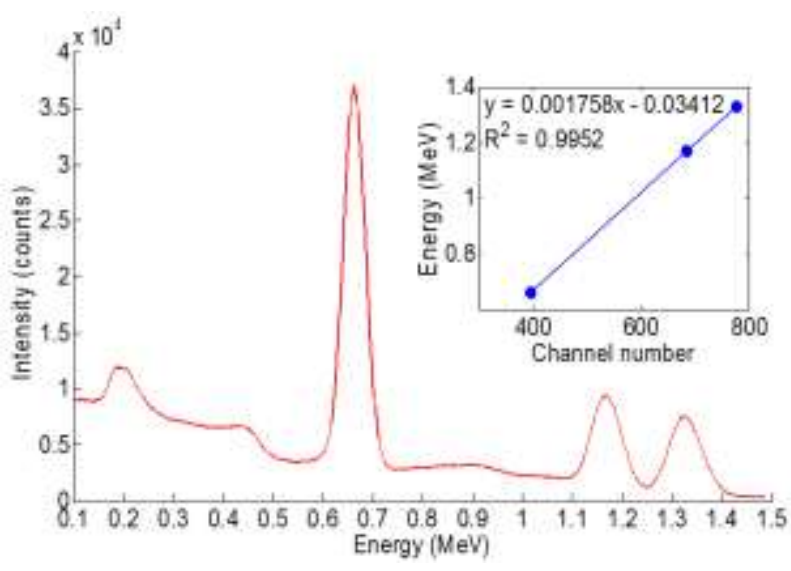

Fig. 2. Spectrum of standard sources of Co-60 and Cs-137 and the MCA calibration curve (inset). 
During the residual radionuclide measurements, the standard radioactive sources were confined in a storage away from the cyclotron cave in order to ensure that the measurements did not experience interference with the radiation from the standard sources. The counting time was determined to be 30 minutes for every measurement.

\section{Radioactivity measurements}

The radioactivity of the residual radionuclides detected on the surface of the cyclotron cave's wall was measured according to relative (indirect) method [14]. A well-characterized radioactive source or standard source having a radioactivity of $A_{s t}$ (in $\mathrm{Bq}$ ) and a count rate of $N_{s t}$ (in counts/second) can be employed to calculate the unknown radioactivity of a radioactive source $\left(A_{x}\right)$ once the source's count $\left(N_{x}\right)$ is measured, following [14]:

$$
A_{x}=\frac{A_{s t}}{N_{s t}} N_{x}
$$

In this experiment, a Co-60 standard source with known activity and count rate is used to measure the radioactivity of the radionuclides detected on the cyclotron wall surface. Note that all measurements were carried out between December 2014 and January 2015, and the CS-30 cyclotron's last operation was in July 2005 at maximum beam energy and current of $26.5 \mathrm{MeV}$ and $1 \mu \mathrm{A}$, respectively.

\section{RESULTS AND DISCUSSION}

\section{Origins of neutrons}

The origins of neutrons have been of great interest due to a wide range of applications. In BATAN's cyclotron cave, since the cyclotron is capable of accelerating protons to up to $26.5 \mathrm{MeV}$, neutrons scattered off the entire wall may originate from the following processes:

(1) Nuclear interactions between protons and the surrounding materials in the cyclotron chamber, particularly $\mathrm{Cu}$. The interactions may occur when, for instance, the energetic protons hit the $\mathrm{Cu}$-based dee electrodes, causing ${ }^{63} \mathrm{Cu}(\mathrm{p}, \mathrm{n}){ }^{63} \mathrm{Zn}$ nuclear reaction. The resulting neutrons escape from the chamber and then strike the cave's wall while the $\mathrm{Zn}-63$ decays with a half-life of 38.5 minutes to the $\mathrm{Cu}-63$ ground state. The threshold proton energy for this particular nuclear reaction is around 4.5 $\mathrm{MeV}[11,12]$, as can be seen from Fig. 3 .
(2) Nuclear interactions between high energy protons and the stainless-steel-based cyclotron chamber which consists of $\mathrm{Fe}, \mathrm{Ni}, \mathrm{Cr}$ and some other, mostly trace, elements. The main neutron source contribution here is mainly from $\mathrm{Fe}$ in which fast neutrons are created instantly as the iron interacts with protons when they are being stripped off their circular paths due to unscheduled distractions such as vacuum failure or unstable power. In this case, protons and iron experience ${ }^{56} \mathrm{Fe}(\mathrm{p}, \mathrm{n}){ }^{56} \mathrm{Co}$ nuclear reaction at a threshold energy of $5.5 \mathrm{MeV}$ (see Fig. 3), and then the radioactive Co-56 decays back to the $\mathrm{Fe}-56$ ground state with a half-life of 77.3 days.

(3) Nuclear interactions with aluminum-based materials used in the cyclotron facilities such as the beam lines. Apart from the main beam line, there are 7 other beam lines installed at BATAN's cyclotron facilities, namely $-45^{\circ}$, $30^{\circ},-15^{\circ}, 0^{\circ}, 15^{\circ}, 30^{\circ}$ and $45^{\circ}$ beam lines. While the other beam lines were rarely used for radioisotope production, the main and the $0^{\circ}$ beam lines were frequently used for radioisotope production, thin layer activation (TLA), and ultra thin layer activation (UTLA) experiments. Proton-bombarded aluminum will become silicon through the ${ }^{27} \mathrm{Al}(\mathrm{p}, \mathrm{n}){ }^{27} \mathrm{Si}$ nuclear reaction with a threshold energy of nearly 5.5 MeV (Fig. 3). The Si-27 radionuclide will eventually decay to Al-27 ground state with a half-life of 4.2 seconds.

(4) Nuclear interactions between protons and targets during radionuclide production, as well as during TLA and UTLA experiments. The nuclear reactions taking place during such activities include ${ }^{18} \mathrm{O}(\mathrm{p}, \mathrm{n})^{18} \mathrm{~F}$, ${ }^{203} \mathrm{Tl}(\mathrm{p}, 3 \mathrm{n}){ }^{201} \mathrm{~Pb} \rightarrow{ }^{201} \mathrm{Tl}$, and ${ }^{56} \mathrm{Fe}(\mathrm{p}, \mathrm{n}){ }^{56} \mathrm{Co}$. The corresponding nuclear cross-sections for F-18, Tl-201 and Co-56 are shown in Fig. 3.

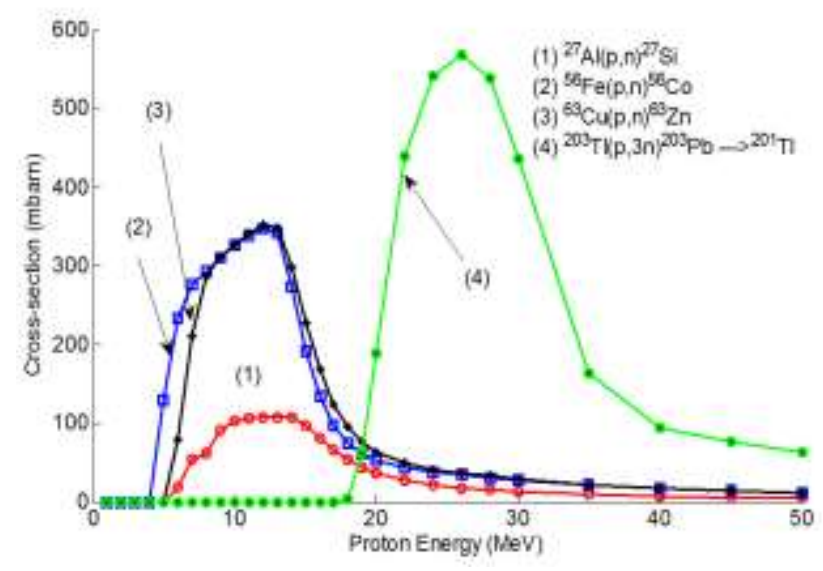

Fig. 3. TALYS-calculated nuclear cross-sections for several $(p, n)$ reactions relevant for the origin of neutrons in BATAN's cyclotron cave. 


\section{Possible neutron-induced radionuclides}

While there is no immediate concern over the main chemical elements such as $\mathrm{O}, \mathrm{Ca}, \mathrm{Mg}, \mathrm{C}, \mathrm{Si}$, $\mathrm{Al}, \mathrm{H}, \mathrm{K}$ due to their insignificant nuclear crosssections should they capture free neutrons, the trace elements found in the concrete wall are of great concerns due to their high excitation functions as can be seen in Fig. 4.
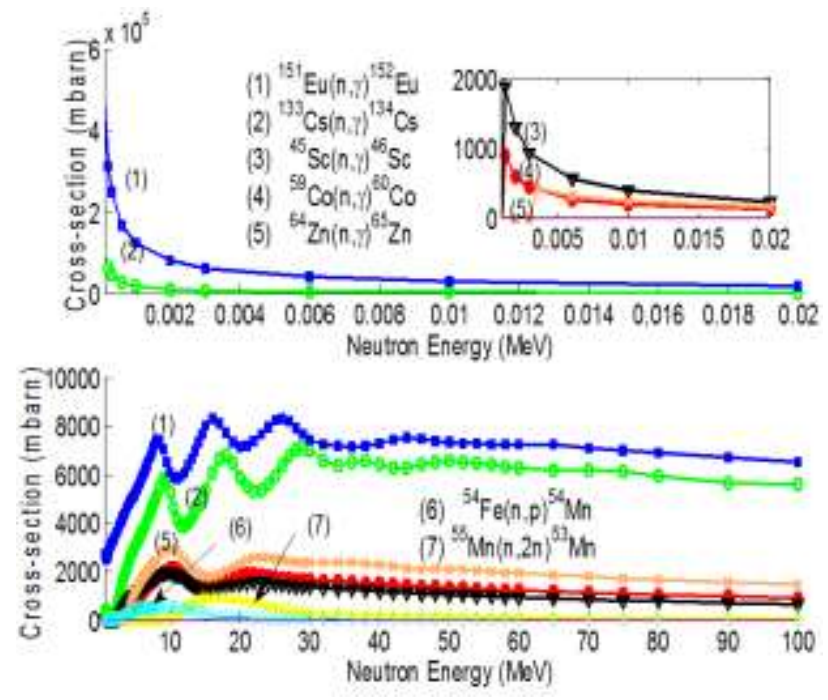

Fig. 4. TALYS-calculated nuclear cross-sections of several trace elements present in the wall of the BATAN's cyclotron cave. In the figure, the excitation functions are shown in the cold, thermal and epithermal neutron regions (top) and slow, fast and relativistic neutron regions (bottom).

In the cold and thermal neutron regions (neutron energies between $0.0 \mathrm{MeV}$ and $0.02 \mathrm{MeV}$ ), the ${ }^{151} \mathrm{Eu}(\mathrm{n}, \gamma){ }^{152} \mathrm{Eu}$ nuclear reaction has the highest nuclear cross-section $\left(\sigma_{\max }=5.85 \times 10^{6}\right.$ mbarn $)$ among the investigated elements while the ${ }^{133} \mathrm{Cs}(\mathrm{n}, \gamma){ }^{134} \mathrm{Cs}$ nuclear reaction cross-section comes second $\left(\sigma_{\max }=2.93 \times 10^{5}\right.$ mbarn $)$. In addition, nuclear cross-sections for ${ }^{45} \mathrm{Sc} \quad(\mathrm{n}, \gamma)^{46} \mathrm{Sc}$, ${ }^{59} \mathrm{Co}(\mathrm{n}, \gamma){ }^{60} \mathrm{Co}$, and ${ }^{64} \mathrm{Zn}(\mathrm{n}, \gamma){ }^{65} \mathrm{Zn}$ reactions are also significantly high whereas others such as ${ }^{58} \mathrm{Fe}(\mathrm{n}, \quad \gamma){ }^{59} \mathrm{Fe}, \quad{ }^{54} \mathrm{Fe}(\mathrm{n}, \mathrm{p}){ }^{54} \mathrm{Mn}, \quad{ }^{23} \mathrm{Na}(\mathrm{n}, 2 \mathrm{n}){ }^{22} \mathrm{Na}$ and ${ }^{55} \mathrm{Mn}(\mathrm{n}, 2 \mathrm{n})^{54} \mathrm{Mn}$ have very low nuclear cross-sections and are insignificant.

In the epithermal and fast neutron regions (neutron energy between $0.5 \mathrm{MeV}$ and $200 \mathrm{MeV}$ ), again, ${ }^{151} \mathrm{Eu}(\mathrm{n}, \gamma){ }^{152} \mathrm{Eu}$ and ${ }^{133} \mathrm{Cs}(\mathrm{n}, \gamma){ }^{134} \mathrm{Cs}$ nuclear reactions rank first and second, respectively, in terms of their excitation functions (over 5000 mbarn at their maximum values). In this particular neutron energy region, ${ }^{45} \mathrm{Sc}(\mathrm{n}, \gamma){ }^{46} \mathrm{Sc}$ and ${ }^{59} \mathrm{Co}(\mathrm{n}, \gamma){ }^{60} \mathrm{Co}$ nuclear reactions exhibit similar behavior and nearly the same values in terms of their cross-sections as a function of the neutron energy, whereas ${ }^{64} \mathrm{Zn}(\mathrm{n}, \gamma)$ ${ }^{65} \mathrm{Zn}$ nuclear reaction possesses a slightly higher cross-section over neutron energies of greater than $5 \mathrm{MeV}$. Both ${ }^{54} \mathrm{Fe}(\mathrm{n}, \mathrm{p}){ }^{54} \mathrm{Mn}$ and ${ }^{55} \mathrm{Mn}(\mathrm{n}, 2 \mathrm{n}){ }^{54} \mathrm{Mn}$, nuclear reactions have cross-sections of lower than 1000 mbarn. Nevertheless, significant cross-sections are observed for ${ }^{55} \mathrm{Mn}(\mathrm{n}, 2 \mathrm{n}){ }^{54} \mathrm{Mn}$ reaction when neutron energy lies between $10 \mathrm{MeV}$ and $30 \mathrm{MeV}$. In general, at $30-\mathrm{MeV}$ and over, the nuclear crosssections for all simulated nuclear reactions tend to level off or slightly decrease with increasing neutron energy. Typical nuclear reactions involving the trace elements present in the wall of BATAN's cyclotron cave might occur; their threshold energies and the energies of the gamma rays emitted are given in Table 2.

Table 2. Possible radionuclides produced by neutron captures in the BATAN cyclotron's concrete wall. The data are compiled from the TALYS calculations as well as references elsewhere $[7,11,12,15]$

\begin{tabular}{|c|c|c|c|c|}
\hline \multirow[t]{2}{*}{ Nuclear reaction } & \multirow{2}{*}{$\begin{array}{c}\text { Half life } \\
\text { (years) }\end{array}$} & \multirow{2}{*}{$\begin{array}{c}\text { Main gamma } \\
\text { energies }\end{array}$} & \multicolumn{2}{|c|}{$\begin{array}{c}\sigma_{\max } \text { at fast neutron } \\
\text { regions below } 17 \\
\mathrm{MeV}\end{array}$} \\
\hline & & & $\begin{array}{c}\text { En } \\
(\mathrm{MeV})\end{array}$ & $\begin{array}{c}\sigma_{\max } \\
(\mathrm{mbarn})\end{array}$ \\
\hline${ }^{58} \mathrm{Fe}(\mathrm{n}, \gamma)^{59} \mathrm{Fe} /$ & 0.122 & $\begin{array}{l}1.291(44 \%) \\
1.099(56 \%)\end{array}$ & 1 & 1.45 \\
\hline${ }^{54} \mathrm{Fe}(\mathrm{n}, \mathrm{p}){ }^{54} \mathrm{Mn}$ & 0.885 & $0.835(99.9 \%)$ & 11 & 510 \\
\hline${ }^{23} \mathrm{Na}(\mathrm{n}, 2 \mathrm{n})^{22} \mathrm{Na}$ & 2.603 & $1.274(100 \%)$ & 16 & 53.5 \\
\hline${ }^{55} \mathrm{Mn}(\mathrm{n}, 2 \mathrm{n})^{54} \mathrm{Mn}$ & 0.855 & 0.835 (99.9\%) & 16 & 869 \\
\hline${ }^{64} \mathrm{Zn}(\mathrm{n}, \gamma){ }^{65} \mathrm{Zn}$ & 0.668 & $1.115(50 \%)$ & 10 & 2970 \\
\hline${ }^{59} \mathrm{Co}(\mathrm{n}, \gamma){ }^{60} \mathrm{Co}$ & 5.271 & $\begin{array}{l}1.17(100 \%), \\
1.33(100 \%)\end{array}$ & 10.5 & 2160 \\
\hline${ }^{133} \mathrm{Cs}(\mathrm{n}, \gamma){ }^{134} \mathrm{Cs}$ & 2.065 & $\begin{array}{l}0.57(23 \%) \\
0.605(98 \%) \\
0.796(99 \%)\end{array}$ & 9.5 & 5840 \\
\hline${ }^{45} \mathrm{Sc}(\mathrm{n}, \gamma)^{46} \mathrm{Sc}$ & 0.230 & $\begin{array}{l}0.889(100 \%), \\
1.12(100 \%)\end{array}$ & 10 & 1940 \\
\hline${ }^{151} \mathrm{Eu}(\mathrm{n}, \gamma){ }^{152} \mathrm{Eu}$ & 13.516 & $1.408(22 \%)$ & 16 & 8310 \\
\hline
\end{tabular}

\section{Identification of the gamma rays}

Following the detection of radioactivity on the surface of the cyclotron cave's wall using the portable spectroscopy system, there are four pronounced energy peaks of gamma rays identified as follows (see Fig. 5):

(1) The first main peak, which lies at around $0.6 \mathrm{MeV}$, is possibly due to either the backscattered gamma ray corresponding to the Compton scattering processes or a full energy peak of Cs-134 from photoelectric effect. Calculated result using Compton scattering equation [14] indicates that the corresponding backscattered gamma ray should emerge at around $0.055 \mathrm{MeV}$, therefore this calculated result rules out any possibility of the backscattered peak around $0.6 \mathrm{MeV}$. Moreover, it favors second explanation in which a full energy peak of Cs-134 occupies this position. Even though Cs-134 has two energy peaks close to each other around $0.6 \mathrm{MeV}(\mathrm{E} \gamma=0.57 \mathrm{MeV}$ and $\mathrm{E} \gamma=0.605)$, they simply cannot be separated by the portable 
spectroscopy system employed in this experiment, thus only a single peak is observed around $0.6 \mathrm{MeV}$. In addition, the decay fraction of the $0.57-\mathrm{MeV}$ gamma ray is only $0.23 \%$, which is much smaller than that of the $0.605-\mathrm{MeV}$ gamma ray $(98 \%)$, therefore the latter dominates the peak.

(2) The second main peak, at nearly $0.8 \mathrm{MeV}$, belongs to the full energy peak of Cs-134 $(\mathrm{E} \gamma=0.796 \mathrm{MeV})$ from photoelectric effect.

(3) The third main peak, around $1.17 \mathrm{MeV}$, is clearly a full energy peak of Co-60 due to photoelectric effect.

(4) The fourth main peak, around $1.33 \mathrm{MeV}$, is also a full energy peak of Co-60 as a result of photoelectric effect.

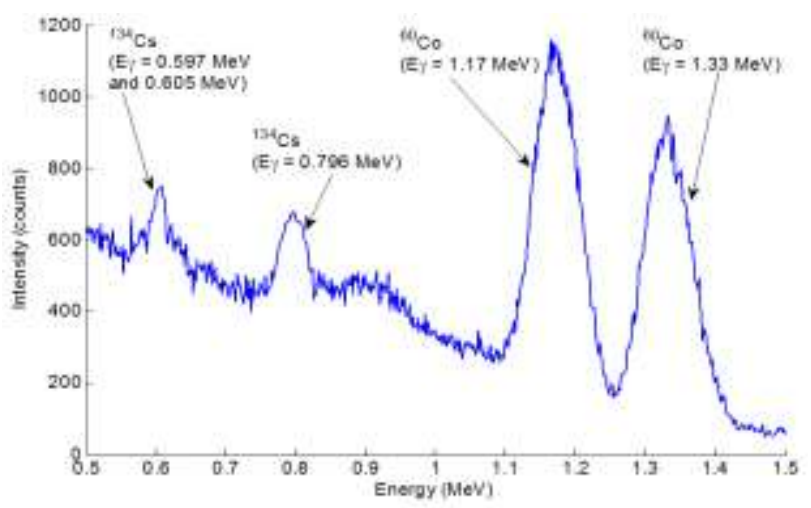

Fig. 5. Spectrum of gamma rays detected on the surface of the BATAN's cyclotron cave's wall.

In conclusion, based on the experimental results and data found in reference [15], the identified gamma peaks correspond to Co-60 and Cs-134 sources. There are no other radionuclides identified on the wall's surface. While ${ }^{151} \mathrm{Eu}(\mathrm{n}, \gamma){ }^{152} \mathrm{Eu}$ nuclear reaction has the highest nuclear cross-section across the entire neutron energy regions as discussed in earlier section, there is no significant count detected from Eu-152 radioinuclide on the wall's surface. The absence of gamma ray radiation, in particular, from Eu-152 and Sc-46 sources is most likely due to the following two reasons:

(1) The atomic ratios of both radioisotopes are very low $\left(5.2 \times 10^{-8}\right.$ and $1.2 \times 10^{-6}$ respectively), too low to generate significant amounts of nuclear reactions when neutrons impinge on the solid elements.

(2) Most neutrons, when first hitting the wall's surface, are presumably fast neutrons instead of thermal neutrons; thus, even though the nuclear cross-section to produce Eu-152 is nearly three times of that of to produce Co-60, the resulting rare earth radioisotope would be insignificant since its atomic fraction in the wall is about $5.2 \times 10^{-5}$ times relative to the Co fraction. Nevertheless, Eu-152 may be observed in a certain depth from the wall's surface when fast neutrons become thermal neutrons as they hit the surrounding atoms.

\section{Experimental angular distribution of the gamma ray intensities}

The distribution of neutrons hitting the wall of BATAN's cyclotron cave can be detected by analyzing the gamma ray intensities recorded by the portable spectrometry system in each point of measurement. For this purpose, the relative intensity of each measurement is plotted against the proton incidence angle in order to obtain the angular distribution of the gamma ray intensity from Co-60 source detected on the wall surface, particularly from the $1.17 \mathrm{MeV}$ gamma ray.

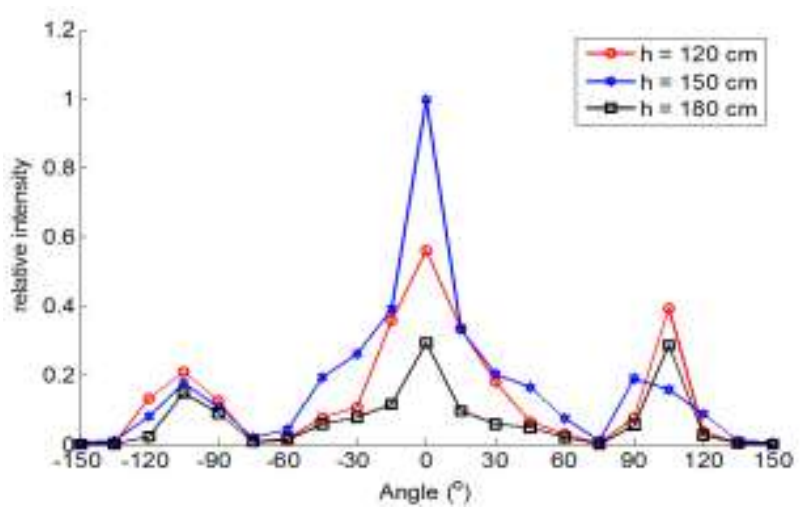

Fig. 6. Angular distribution of the Co-60's gamma ray intensity

Based on the experimental data, the angular distribution of the gamma ray intensity is nearly symmetrical for both positive and negative angles and also for the three investigated heights ( $\mathrm{h}=120 \mathrm{~cm}, 150 \mathrm{~cm}$, and $180 \mathrm{~cm}$ ) as shown in Fig. 6 , in which the highest intensities occur at $0^{\circ}$ incidence angle, and then they drop steeply with increasing incidence angle of up to $\pm 75^{\circ}$. The gamma ray intensities increase again and peak at incidence angle of $\pm 105^{\circ}$, though the intensities at $105^{\circ}$ incidence angle are, in general, slightly higher than that at the $-105^{\circ}$ angle. The Co-60 intensities eventually falls down again at larger incidence angles. In addition, the angular distribution of the Cs-134 intensity is found to be similar to the Co-60's; thus it will not be discussed further in this paper.

One noticeably interesting feature about the angular distribution is that the gamma ray intensity emitted from the detected Co-60 is at its maxima at $0^{\circ}$ instead of at larger angles. The feature can be explained as follows: during the radionuclide production and material analysis experiments at BATAN's cyclotron cave, a large amount of fast 
neutrons generated from the $\mathrm{X}(\mathrm{n}, \mathrm{p}) \mathrm{Y}$ and $\mathrm{X}(\mathrm{p}, 2 \mathrm{n}) \mathrm{Y}$ are scattered off the target at incidence angles of around $0^{\circ}$. This could happen when the target contains heavier atoms such as $\mathrm{Fe}, \mathrm{Cu}, \mathrm{Tl}$ atoms since their neutron scattering cross-sections are very high, higher than that of lighter atoms such as $\mathrm{H}$ atoms present in enriched water $\left(\mathrm{H}_{2}{ }^{18} \mathrm{O}\right)$ target [12]. Based on the TALYS-calculated fast neutron scattering cross-sections, heavier atoms involved in the radionuclide production at BATAN's cyclotron facilities, such as $\mathrm{Tl}, \mathrm{Cu}, \mathrm{Ni}, \mathrm{Fe}, \mathrm{Cr}$, and $\mathrm{Al}$, raise the cross-sections in the scattering angles ranging from $0^{\circ}$ to $50^{\circ}$, as can be seen in Fig. 7 for neutron energy of $10 \mathrm{MeV}$. Meanwhile for thermal neutrons $(\mathrm{E}=0.0025 \mathrm{MeV})$, the scattering cross-sections are nearly flat across the incidence angles. Since the majority of the neutrons hitting the cyclotron wall's surface are fast neutrons, the thermal neutrons would not contribute significantly to the detected radioactivity.

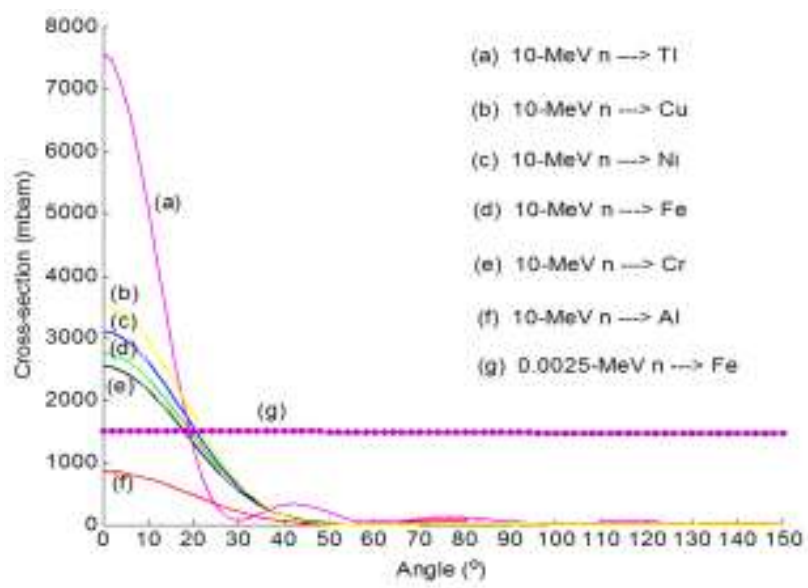

Fig. 7. TALYS-calculated angular distribution of $10-\mathrm{MeV}$ neutron scattering cross-sections incident into $\mathrm{Tl}, \mathrm{Cu}, \mathrm{Ni}, \mathrm{Fe}$, $\mathrm{Cr}$, and $\mathrm{Al}$. The $0.0025-\mathrm{MeV}$ neutron scattering cross-sections in Fe target are also shown in the figure as a comparison.

In addition, the pronounced intensity rise at incidence angles between $75^{\circ}$ and $150^{\circ}$ is most likely due to fast neutrons with lower energy than $10 \mathrm{MeV}$, especially neutrons with energy between $0.5 \mathrm{MeV}$ and $5 \mathrm{MeV}$ that hit Fe targets in the TLA and UTLA experiments. At those particular energy and incidence angle ranges, the TALYS-calculated scattering cross-sections peak at around $100^{\circ}$ incidence angle as shown in Fig. 8, and are over 450 mbarn for $0.5-\mathrm{MeV}$ neutrons, which are high enough to generate significant amounts of radioactivity on the cyclotron wall surface.

Therefore, this behavior is in line with the experimental results in which pronounced intensity emerges at around $100^{\circ}$ incidence angle. It shall be noted that the higher the neutron energy incident into $\mathrm{Fe}$ target is, the lower the scattering crosssection is.

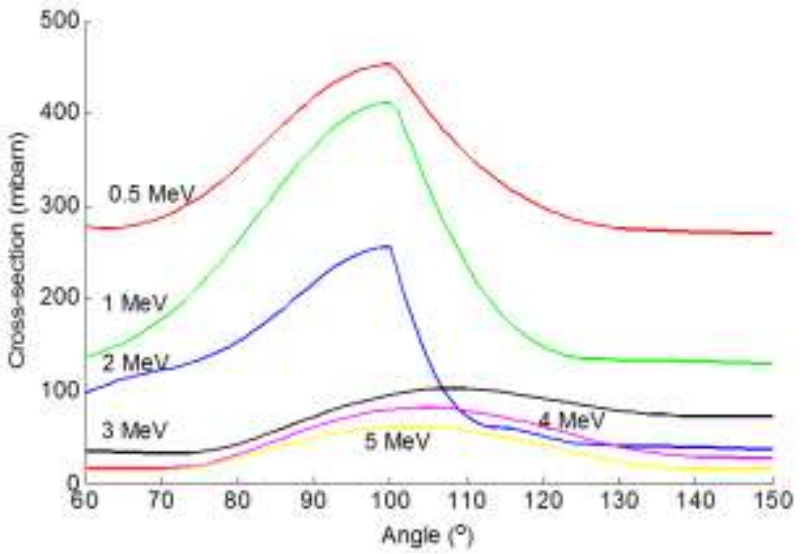

Fig. 8. TALYS-calculated angular distribution of neutron scattering cross-sections incident into $\mathrm{Fe}$.

\section{Measured Co-60 activities}

Using the relative method as described in the Experimental Section, the Co-60 radioactivity is measured and the results are listed in Table 3. The maximum radioactivity, which occurs at $0^{\circ}$ incidence angle and $\mathrm{h}=1.5 \mathrm{~m}$, is $6.113 \mathrm{kBq}$ $(=0.165 \mu \mathrm{Ci})$. At the levels of radioactivity detected on the cyclotron wall (correspond to a maximum exposure of $0.015 \mu \mathrm{Sv} / \mathrm{hour}=0.13 \mathrm{mSv} /$ year or lower), there should be no immediate concerns over the safety of the radiation workers since the exposures are well below the permissible occupational exposure of $20 \mathrm{mSv} /$ year [16]. Again, the measured Cs-134 radioactivities are not discussed further here since they contribute to much lower exposures than those of Co-60.

Tabel 3. Radioactivity of Co- 60 measured at different incidence angles and heights

\begin{tabular}{lccc}
\hline \multirow{2}{*}{ Angle (deg.) } & \multicolumn{3}{c}{ Radioactivity (kBq) } \\
\cline { 2 - 4 } & $\mathrm{h}=1.2 \mathrm{~m}$ & $\mathrm{~h}=1.5 \mathrm{~m}$ & $\mathrm{~h}=1.8 \mathrm{~m}$ \\
\hline 150 & 0.012 & 0.029 & 0.009 \\
135 & 0.028 & 0.068 & 0.020 \\
120 & 0.228 & 0.555 & 0.166 \\
105 & 2.461 & 6.003 & 1.801 \\
90 & 0.493 & 1.202 & 0.361 \\
75 & 0.027 & 0.067 & 0.020 \\
60 & 0.191 & 0.467 & 0.140 \\
45 & 0.421 & 1.027 & 0.308 \\
30 & 0.522 & 1.272 & 0.382 \\
15 & 0.850 & 2.074 & 0.622 \\
0 & 2.506 & 6.113 & 1.834 \\
-15 & 1.003 & 2.445 & 0.734 \\
-30 & 0.677 & 1.650 & 0.495 \\
-45 & 0.501 & 1.223 & 0.367 \\
-60 & 0.110 & 0.269 & 0.081 \\
-75 & 0.055 & 0.135 & 0.041 \\
-90 & 0.788 & 1.922 & 0.577 \\
-105 & 2.566 & 6.258 & 1.877 \\
-120 & 0.211 & 0.515 & 0.155 \\
-135 & 0.025 & 0.062 & 0.019 \\
-150 & 0.009 & 0.022 & 0.007 \\
\hline
\end{tabular}




\section{CONCLUSION}

Detection and measurements of radioactivity on the wall of the BATAN's cyclotron cave have been carried out using a portable gamma spectrometry system in order to identify and study the angular distribution of the residual radionuclides. Experimental data indicate that there are two radionuclides, namely Co-60 and Cs-134, that were significantly detected on the wall's surface. Analysis of the angular distribution on three different heights $(\mathrm{h}=1.2 \mathrm{~m}, 1.5 \mathrm{~m}, 1.8 \mathrm{~m})$ highlights that the maximum intensities of Co-60 and Cs-134 occur around $0^{\circ}$ incidence angle. The pronounced increase in the incidence angle range between $90^{\circ}$ and $150^{\circ}$ is presumably due to an increase in the scattering cross-sections of lower energy fast neutrons. Meanwhile, measurement of their radioactivity shows a maximum of only $0.13 \mathrm{mSv} / y e a r$ exposure is detected at $1 \mathrm{~m}$ distance, which means that it is much lower than the permissible occupational exposure of $20 \mathrm{mSv} / \mathrm{year}$.

\section{ACKNOWLEDGMENT}

The authors gratefully express their thanks to the generous contributions of Mr. Serly A. Sarunggalo, and Mr. Rajiman to the discussion during the paper's write-up. The funding from BATAN for the success of this research is also acknowledged.

\section{REFERENCES}

1. I. Kambali, Atom Indonesia Journal 40 (2014) 129.

2. I. Kambali, T. Heryanto, Rajiman et al., Atom Indonesia Journal 37 (2011) 5.

3. D.P. Singh, V.R. Sharma, A. Yadav et al., Journal of Nuclear Physics, Material Sciences, Radiation and Applications 1 (2013) 13.

4. E. Corniani, M. Jech, T. Wopelka et al., Journal of Mechanical Engineering Science 226 (2012) 319.
5. Anonymous, MCNPX User's Manual, Version 2.7.0, D.B. Pelowitz (Ed), Los Alamos National Laboratory Report LA-CP-11-00438 (2011) 1.

6. H. Paul, AIP Conf. Proc. 1525 (2013) 309. DOI: $10.1063 / 1.4802339$

7. J.J. Martínez-Serrano and A.D. de los Ríos, Medical Physics 37 (2010) 6015.

8. L. Trnkova, T. Trojek and L. Thinova, Applied Radiation and Isotopes 68 (2010) 832.

9. I. Yamaguchi, K. Kimura, T. Fujibuchi et al., Radiation Protection Dosimetry 146 (2011) 167.

10. T. Fujibuchi, A. Nohtomi, S. Baba et al., Ann. Nucl. Med. 2014 (2014) 84.

DOI 10.1007/s12149-014-0918-6.

11. A.J. Koning, S. Hilairey and M. Duijvestijn, User's Manual of TALYS 1.4 Codes: A Nuclear Reaction Program, Petten, The Netherlands (2011) 1.

12. A.J. Koning and D. Rochman, Modern Nuclear Data Evaluation With The TALYS Code System, Nuclear Data Sheets 113 (2012) 2841.

13. S.A. Sarungallo, Basic Design of the BATAN's cyclotron Building, in: Training on Cyclotron Technology and Application for Technicians, Center for Radioisotope and Radiopharmaceuticals BATAN, Tangerang (1993) 14. (in Indonesian)

14. W.B. Mann, A. Rytz and A. Spernol, Radioactivity Measurements: Principles and Practice. Elsevier Publishing Co., New York (2012) 113.

15. M.F. L'Annunziata, Handbook of Radioactivity Analysis, $3^{\text {rd }}$ ed., Massachusets: Academic Press (2012) 1305.

16. Anonymous, IAEA Safety Standards DS453: Occupational Radiation Protection, Vienna: IAEA (2014). 